\title{
PAPER
}

\section{Clinical surveillance of carpal tunnel syndrome in two areas of the United Kingdom, 1991-2001}

\author{
J D P Bland, S M Rudolfer
}

J Neurol Neurosurg Psychiatry 2003;74:1674-1679

See end of article for authors' affiliations

.....................

Correspondence to: Dr Jeremy D P Bland, EEG Department, Kent and Canterbury Hospital, Ethelbert Road, Canterbury CT1 3NG, UK'; ibland@ cix.compulink.co.uk

Received 12 January 2003 In revised form 23 April 2003

Accepted 25 April 2003
Objective: To study the demographic characteristics of patients with carpal tunnel syndrome and changes in incidence over time.

Methods: Prospective collection of neurophysiological and clinical data on all patients presenting to the subregional department of clinical neurophysiology in Canterbury, UK, from 1992 to 2001 and to the electromyography clinic in St Luke's Hospital, Huddersfield, UK, from 1991 to 1993.

Results: 6245 new cases of neurophysiologically confirmed carpal tunnel syndrome were identified in Canterbury and 590 in Huddersfield. The average annual incidences (per 100 000) were 139.4 for women and 67.2 for men in East Kent, and 83.2 for women and 48.0 for men in Huddersfield. Corrected to the WHO European standard population these rates were 120.5 for women and 60.0 for men in East Kent, and 61.5 for women and 35.0 for men in Huddersfield. Between 1992 and 2001 there was an increase in the number of confirmed cases in East Kent but a decrease in their average severity. The age distributions were bimodal with a peak in the 50-54 age group and a second peak between 75 and 84 years. Over half the cases were bilateral. The disorder was consistently worse in the elderly, and more severe in men than in women in all age groups.

Conclusions: The age distributions of unselected cases of carpal tunnel syndrome in both clinics differ markedly from that usually portrayed in surgical series. There was a significant increase in cases diagnosed between 1992 and 2001 in Canterbury, probably the result of increased ascertainment of milder cases. Median nerve impairment is more severe in the elderly and in men at all ages.
M any investigators have described populations of patients with carpal tunnel syndrome since Phalen originally drew general attention to the condition in the 1950s. ${ }^{12}$ However, data on its epidemiology remain conflicting, with wide variations in estimates of incidence and demographic characteristics of affected individuals, depending on the case ascertainment methods used. Population studies where symptoms are actively sought $t^{3-5}$ report prevalences of $10-20 \%$ for symptoms and $5-10 \%$ for definite diagnoses. Estimates based on recording of cases presenting for treatment report incidences of three to six new cases per 1000 person-years. ${ }^{67}$ It is clear that many more cases are identified by population surveys than by surveillance of routine clinical practice.

Attempts to establish incidence and prevalence are further impeded by the lack of any generally agreed definition of the syndrome. A surveillance definition based on the occurrence of symptoms proposed by the American National Institute for Occupational Safety and Health ${ }^{8}$ is too inclusive for clinical use. A consensus paper has suggested that case definitions including nerve conduction studies should be used where possible. ${ }^{9}$ There remains considerable uncertainty about the sensitivity and specificity of nerve conduction studies, which are variously estimated to have a false negative rate of $1.5 \%{ }^{10}$ to $16 \%{ }^{11}$ and a false positive rate of up to $46 \% .^{12}$ Nevertheless, other tests that have been proposed-including computed tomography, magnetic resonance imaging and ultrasound imaging, forms of quantitative sensory testing such as vibrometry, and thermography-have not been shown superior to nerve conduction studies nor gained widespread acceptance. Nerve conduction studies remain the investigation of choice in cases of diagnostic doubt. ${ }^{13}$

Carpal tunnel syndrome is often said to be increasing in incidence, and some population studies have endorsed this view, ${ }^{6}$ but there have been few reports of data collected in a similar way over a long period to document changes in incidence and diagnosis. Studies of compensation data do not show a consistent increase over recent years. ${ }^{14}$ The Mayo clinic data from 1961 to $1980^{7}$ provide the longest time series but these data were collected at a time when diagnostic methods were changing and awareness of the condition among clinicians was still increasing. The investigators attributed the increasing incidence they found to greater ascertainment rather than to an underlying increase in the condition itself. One study using similar methods to ours is available from Italy. Neurophysiologically confirmed cases of carpal tunnel syndrome were collected over an eight year period and showed an increasing incidence in men but not in women. ${ }^{15}$

The demographic characteristics of patients with carpal tunnel syndrome were first described by Phalen ${ }^{1}$ and many subsequent series have reproduced his findings of a marked female preponderance and a peak incidence at the age of about 55 to 60 years. There have, however, been one or two series with differing findings, notably the Rochester data, which showed a progressively increasing incidence with age in men only, and a study of carpal tunnel decompression surgery from Ontario, ${ }^{16}$ which showed the same increasing incidence with age in men, but also a bimodal distribution of age in women, with peaks at 54 and 79 years. In contrast, the recent Italian study showed a unimodal age distribution in women but a bimodal one in men. ${ }^{15}$

Data on patients presenting with carpal tunnel syndrome in the East Kent subregion in the United Kingdom have been collected in the same way since mid-1991 and this paper summarises the characteristics of this large population. The data are compared with another series of UK patients with carpal tunnel syndrome collected between 1991 and 1993 in Huddersfield, West Yorkshire. 


\section{METHODS}

East Kent is served by three district general hospitals and 300 general practitioners. Nerve conduction studies for carpal tunnel syndrome are provided at only one site, the Kent and Canterbury Hospital, for both private and NHS patients. In 1990 agreement was reached with all the secondary care clinicians who commonly saw patients with carpal tunnel syndrome that all cases would be referred for nerve conduction studies before surgery, and from 1995 onwards general practitioners were also encouraged to make direct referrals for nerve conduction studies before onward referral to orthopaedic or rheumatology specialists for treatment. Waiting times for nerve conduction studies have been kept shorter than those for day case carpal tunnel decompression throughout the study period.

The great majority of cases who come to medical attention thus present for nerve conduction studies at a central point, at which it is possible to collate symptomatic, demographic, and nerve conduction study data. Since 1992 all patients have been given a symptom questionnaire to complete before their nerve conduction studies, and standard clinical variables are recorded in all cases..$^{17} \mathrm{~A}$ standardised method of grading the severity of the nerve conduction study findings in carpal tunnel syndrome was introduced in 1991 using a six point scale. ${ }^{18}$ Reaching the first point of this scale requires that two different, sensitive, comparative tests for the syndrome are positive. Examples of these tests include comparison of the median and ulnar sensory latencies at the wrist on ring finger stimulation, and comparison of the motor terminal latency of the ulnar nerve to the second palmar interosseous muscle with the motor terminal latency of the median nerve to the second lumbrical.

For the purposes of this study the case definition of carpal tunnel syndrome required that a clinician had suspected the diagnosis and that nerve conduction studies were positiveat least grade 1 on the Canterbury scale-in one or both hands. All data on carpal tunnel syndrome collected in the neurophysiology department are stored in a combined clinical and administrative database. In addition, data on the number of decompression procedures undertaken on East Kent residents were obtained from the hospital activity data held by the East Kent Health Authority. Population data for East Kent came from the 1991 national UK census. A certain number of patients are referred to Canterbury for nerve conduction studies from outside the East Kent Health Authority area, so district of residence was determined from the patients' postcodes and used to exclude patients from outside the area from the analysis.

To establish the age distribution of the patients, we were also able to compare the demographic data with another series of 851 patients referred to the late Dr John L James, consultant physician, St Luke's Hospital, Huddersfield, UK, for carpal tunnel syndrome investigation between March 1991 and December 1993, ${ }^{19}$ but whose age distribution has not previously been reported. At this time Dr James was the only provider of nerve conduction studies in that area. Patients were referred to Dr James from general practitioners, orthopaedic and other surgeons, as well as consultant physicians, in the Huddersfield and Calderdale Health Authorities. In that population neurophysiological confirmation of carpal tunnel syndrome required a distal median motor latency of $>4.6 \mathrm{~ms}$ combined with a median sensory nerve action potential of $<15 \mu \mathrm{V}$. Age distributions for patients in these health authorities came from the 1991 national UK census.

\section{RESULTS}

\section{Incidence}

Between 1992 and 2001, 11233 tests were done in which a diagnosis of carpal tunnel syndrome was involved, including cases referred with another diagnosis but where neurophysiological evidence of median nerve impairment at the wrist was found and where symptoms were felt to be consistent with carpal tunnel syndrome. Of these tests, 494 were done for follow up purposes, usually after surgical treatment, and were excluded from further analysis. A few patients were referred on two occasions with the same presenting symptoms and these cases were only counted once at the first presentation. After these exclusions there remained data on 10739 patients, of whom 6245 proved to have neurophysiologically confirmed carpal tunnel syndrome. A summary of the annual numbers and sex ratio is shown in table 1, along with the numbers of surgical decompressions undertaken.

The female population of East Kent in 1991 was 308158 and the male population 290 156. Thus the mean annual incidence of new cases of carpal tunnel syndrome during the study period was 139.4 cases/100 000 for women and 67.2 cases/100 000 for men, a female to male ratio of 2.07. These figures were then corrected to the World Health Organisation European standard population to facilitate comparison between datasets. Mean annual incidences calculated in this way are shown in table 2 for Canterbury and Huddersfield data, with rates from an Italian study ${ }^{15}$ for comparison.

So far as surgical procedures are concerned, the activity data available from East Kent Health Authority were compiled by financial year (April to March). There is, however, a waiting list for decompression surgery in East Kent, so there is no absolute correspondence between the cases confirmed by nerve conduction studies during one year and the cases arriving at hospital for surgery in that year. We have chosen to show surgery data for April 1992 to March 1993 alongside the diagnosis figures for January to December

Table 1 Neurophysiologically confirmed cases of carpal tunnel syndrome in East Kent 1992-2001

\begin{tabular}{|c|c|c|c|c|c|c|c|c|c|}
\hline Year & $\begin{array}{l}\text { Total tests } \\
\text { performed with } \\
\text { CTS as diagnosis }\end{array}$ & $\begin{array}{l}\text { Tests } \\
\text { follov }\end{array}$ & $\begin{array}{l}\text { ormed for } \\
\text { diagnosis }\end{array}$ & $\begin{array}{l}\text { Discrete CTS } \\
\text { cases identified }\end{array}$ & $\begin{array}{l}\text { Referrals } \\
\text { confirmed as } \\
\text { CTS }\end{array}$ & $\begin{array}{l}\text { Female CTS } \\
\text { cases }\end{array}$ & $\begin{array}{l}\text { Male CTS } \\
\text { cases }\end{array}$ & $\begin{array}{l}\text { Female/male } \\
\text { ratio }\end{array}$ & $\begin{array}{l}\text { Surgical } \\
\text { operations }\end{array}$ \\
\hline 1992 & 820 & 26 & 794 & 474 & $60 \%$ & 352 & 122 & 2.89 & 330 \\
\hline 1993 & 912 & 24 & 888 & 550 & $62 \%$ & 371 & 179 & 2.07 & 424 \\
\hline 1994 & 1055 & 12 & 1043 & 632 & $61 \%$ & 439 & 193 & 2.27 & 442 \\
\hline 1995 & 1073 & 29 & 1044 & 566 & $54 \%$ & 380 & 186 & 2.04 & 508 \\
\hline 1996 & 1116 & 34 & 1082 & 612 & $57 \%$ & 420 & 192 & 2.19 & 508 \\
\hline 1997 & 1052 & 37 & 1015 & 520 & $51 \%$ & 372 & 148 & 2.51 & 456 \\
\hline 1998 & 1143 & 50 & 1093 & 579 & $53 \%$ & $41 \overline{2}$ & 167 & 2.47 & 465 \\
\hline 1999 & 1295 & 74 & 1221 & 716 & $59 \%$ & 465 & 251 & 1.85 & 480 \\
\hline 2000 & 1125 & 94 & 1031 & 627 & $61 \%$ & 414 & 213 & 1.94 & 436 \\
\hline 2001 & 1642 & 114 & 1528 & 969 & $63 \%$ & 670 & 299 & 2.24 & 597 \\
\hline TOTAL & 11233 & 494 & 10739 & 6245 & $58 \%$ & 4295 & 1950 & 2.20 & 4646 \\
\hline
\end{tabular}


Table 2 Annual sex specific incidence of carpal tunnel syndrome in Canterbury and Huddersfield corrected to the WHO European standard age distribution; comparable data from Mondelli et al (Siena, Italy) ${ }^{15}$ are presented for comparison

\begin{tabular}{lccl}
\hline Dataset & Female & Male & Female/male ratio \\
\hline Canterbury & 120 & 60 & 2.0 \\
Huddersfield & 62 & 35 & 1.8 \\
Siena & 506 & 139 & 3.6 \\
\hline
\end{tabular}

1992, and similarly for subsequent years, in both table 1 and fig 1.

\section{Trend over time}

The annual numbers of new cases diagnosed year by year and the numbers of carpal tunnel decompression operations are shown graphically in fig $\mathrm{l}$. There was a rising trend in the numbers of both male and female cases and in surgery for carpal tunnel syndrome. Staff shortages in the neurophysiology department during the year 2000 caused some restriction in total capacity and a small waiting list developed. This was cleared during 2001 but the effect is to reduce the apparent numbers during 2000 and increase them during 2001.

To test the statistical significance of the increasing trend in numbers by sex, a Poisson regression model was fitted to the data, with year and sex as the independent variables. This confirmed there was no statistical evidence of an interaction between sex and year $(p=0.0975)$ but evidence $(p<0.0001)$ of an increase in numbers of cases and operations over the 10 year period and a difference in incidence between the sexes. The analysis was repeated after excluding the artificially inflated 2001 data, with similar results $(p<0.0001$ for year and sex separately, and $\mathrm{p}=0.0284$ for the year-sex interaction)

\section{Severity of carpal tunnel syndrome}

For all patients the neurophysiological grade of the worst hand was recorded. The average value of this severity measure for all cases seen with confirmed carpal tunnel syndrome during each year is shown in fig 2 . There was a clear downward trend, suggesting that milder disease was being detected as time passed. The syndrome in female patients was consistently milder than in male patients. An analysis of covariance (ANCOVA) was carried out to examine

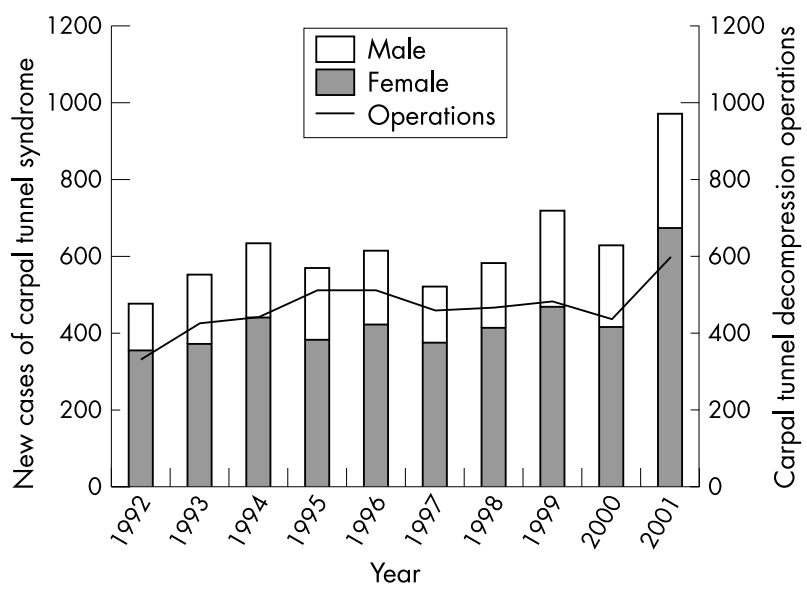

Figure 1 Numbers of new cases of neurophysiologically confirmed carpal tunnel syndrome arising, and carpal tunnel decompression operations performed, in East Kent residents by year.

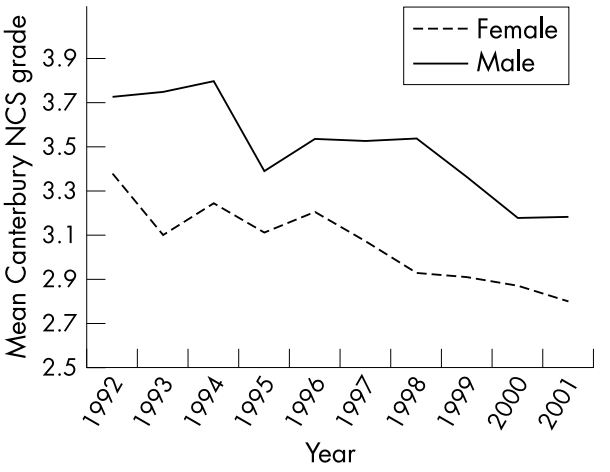

Figure 2 Average neurophysiological severity (on the Canterbury scale) of new cases of carpal tunnel syndrome detected each year, male and female.

the time trend and sex effect on the average neurophysiological grade of the worst hand. ANCOVA considers whether the grades are well fitted by the two regression lines of grade on year corresponding to male and female subjects. There was no statistical evidence of a year-sex interaction $(p=0.5579)$ - that is, no reason to reject the parallelism of the regression lines. Both sex and year proved statistically significant $(p<0.0001)$, statistical evidence that the data fitted two distinct lines with the same (negative) slope.

\section{Age and sex distribution}

Absolute numbers of cases with neurophysiologically confirmed carpal tunnel syndrome were calculated for each chronological year of age at the time of nerve conduction studies, but population data for East Kent were only available from the 1991 UK census for five year age bands. Thus, age group specific annual incidence rates are shown in fig 3 for these five year age bands. For comparison with the East Kent population, fig 3 also shows the same figures calculated for the Huddersfield population between 1991 and 1993.

\section{Neurophysiological severity in relation to age}

In both men and women, there was a progressive increase in the severity of median nerve impairment with age (fig 4). ANCOVA was carried out to examine the age and sex effect on the mean Canterbury nerve conduction study grade of the

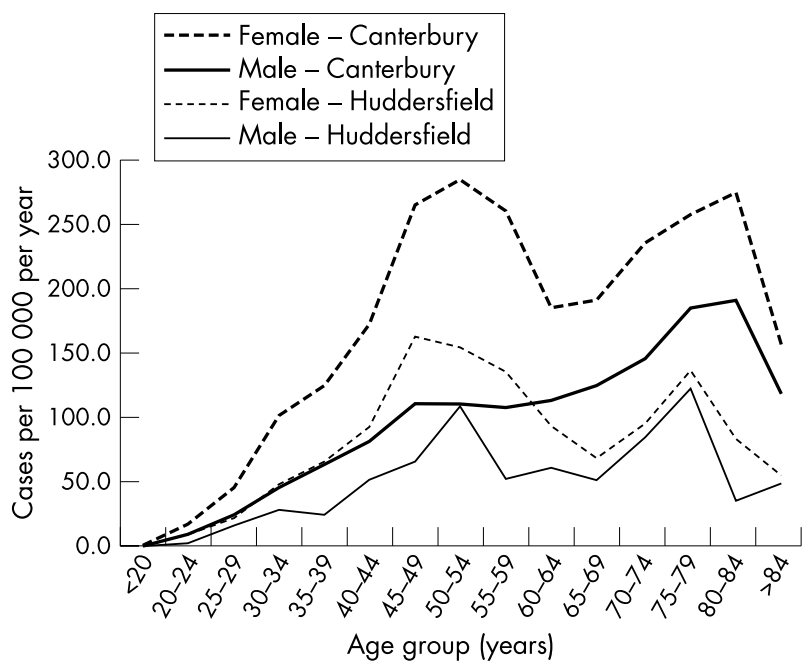

Figure 3 Annual age and sex specific incidences of neurophysiologically confirmed carpal tunnel syndrome in Canterbury and Huddersfield. 


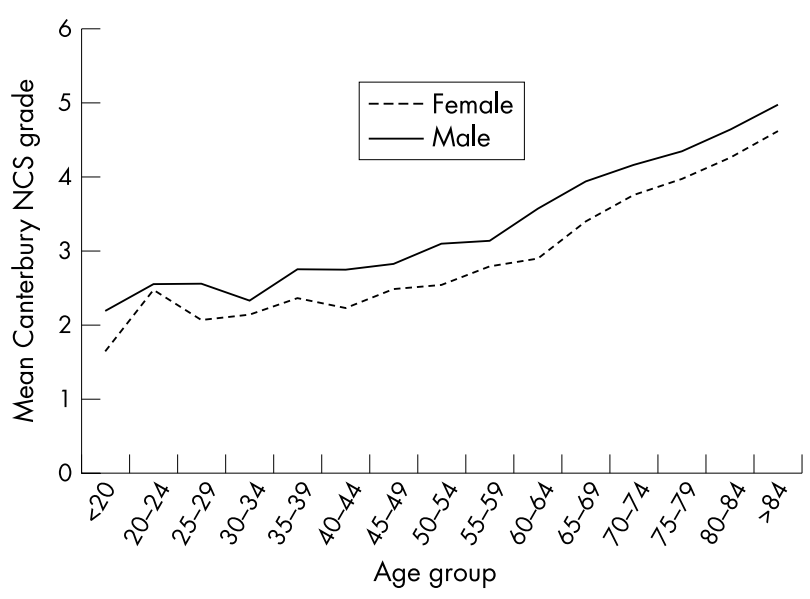

Figure 4 Plot of mean neurophysiological severity, on the Canterbury scale, of carpal tunnel syndrome against age for men and women.

worst hand. For the purposes of analysis, the midpoint of the age groups (apart from the first and last) was used as the age covariate. As the age groups increased in five year intervals, the first age point was taken as 17 and the last as 89 . There was no statistical evidence of an age-sex interaction $(p=0.8063)$, but there was evidence $(p<0.0001)$ of an age effect and a sex effect $(p=0.0003)$ after omitting the interaction term.

\section{Distribution of severity}

Figure 5 shows the percentage distribution of neurophysiological abnormalities by Canterbury grade in men and women. There was a preponderance of grade 1 and grade 2 cases in women.

\section{Laterality of carpal tunnel syndrome}

Table 3 shows the relation between handedness and whether the patient presents mainly with right, left, or bilateral neurophysiological median impairment. Patients with a previous history of carpal tunnel decompression on one or both sides were excluded from the analysis. It can be seen that patients overwhelmingly presented first with the dominant hand, and that this effect was seen in both left and right handed individuals, with only $14 \%$ overall presenting with the syndrome in the non-dominant hand. To explore this further a subset of more recent patients was asked to indicate in more detail the lateralisation of their

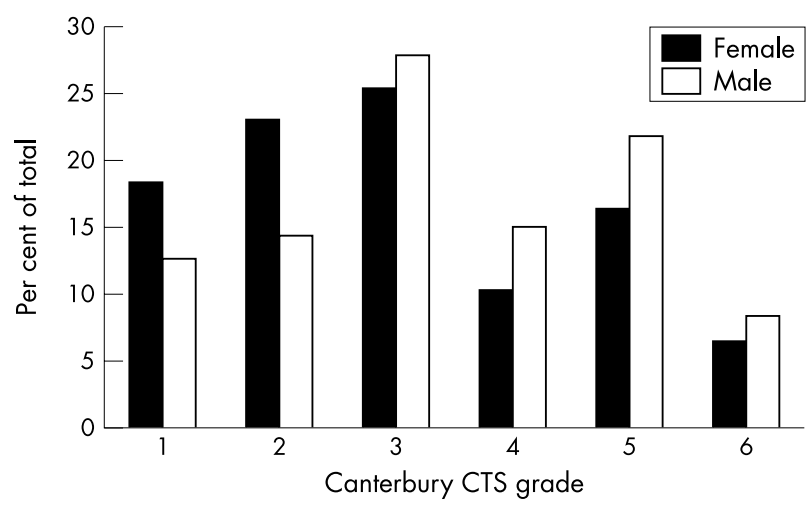

Figure 5 Distribution of cases of carpal tunnel syndrome by Canterbury neurophysiological grade for men and women.

symptoms. Patients with a previous history of carpal tunnel decompression and those who described themselves as ambidextrous were excluded. The results, in 2605 patients with neurophysiologically confirmed carpal tunnel syndrome, are shown in table 4. There was also a high degree of agreement between the patient's assessment of which hand was worse and the neurophysiological findings in East Kent (table 5).

\section{DISCUSSION}

This is the largest study so far of the demographics of carpal tunnel syndrome using a case definition that includes nerve conduction studies. The Canterbury dataset is one of only three to compare incidence rates of neurophysiologically confirmed cases over a period of more than five years using a consistent methodology. Case ascertainment for East Kent residents is believed to be almost complete for cases of medically diagnosed carpal tunnel syndrome, as a result of the well defined management protocol in the district. Circumstantial evidence in support of this is provided by the fact that it is almost unknown for East Kent patients to attend for investigation of failed carpal tunnel decompression without having had preoperative nerve conduction studies. The basic demographic data show the expected excess of female over male patients, but the ratio $(2.07: 1)$ is less than that reported elsewhere in Europe ${ }^{15}$ and markedly less than in Argentina (10:1 $)^{20}$ or Korea (23:1). ${ }^{21}$ The corrected overall annual incidences for the two United Kingdom populations presented here are markedly lower than reported from Italy ${ }^{15}$ during the period (table 2). Whether there are genuine

Table 3 Laterality of median neuropathy on nerve conduction studies in relation to handedness

\begin{tabular}{lllll}
\hline & \multicolumn{2}{l}{ Handedness } & & \\
\cline { 2 - 3 } CTS found on nerve conduction studies & Ambidextrous & Left & Right & Total \\
\hline Canterbury & & & & \\
Bilateral & $28(71.8 \%)$ & $280(54.2 \%)$ & $3019(55.3 \%)$ & $3327(55.3 \%)$ \\
Left & $4(10.3 \%)$ & $153(29.6 \%)$ & $712(13 \%)$ & $869(14.4 \%)$ \\
Right & $7(17.9 \%)$ & $84(16.2 \%)$ & $1731(31.7 \%)$ & $1822(30.3 \%)$ \\
Total & 39 & 517 & 5462 & 6018 \\
Proportion of total population & $0.6 \%$ & $8.6 \%$ & $90.8 \%$ & $100.0 \%$ \\
Huddersfield & & & & \\
Bilateral & $4(50 \%)$ & $29(60 \%)$ & $351(66 \%)$ & $384(65.5 \%)$ \\
Left & 0 & $7(15 \%)$ & $43(8 \%)$ & $50(9 \%)$ \\
Right & $4(50 \%)$ & $12(25 \%)$ & $136(25.7 \%)$ & $152(25.9 \%)$ \\
Total & 8 & 48 & 530 & 586 \\
Proportion of total population & $1.4 \%$ & $8.2 \%$ & $90.4 \%$ & $100.0 \%$ \\
\hline
\end{tabular}

Canterbury: simple $\kappa=0.0380$, ASE 0.0038, $\mathrm{p}<0.0001$; Huddersfield: simple $\kappa=0.0004$, ASE 0.0114, $\mathrm{p}=0.97$. 
Table 4 Relation between handedness and side of worst subjective symptoms at first presentation in neurophysiologically confirmed carpal tunnel syndrome

\begin{tabular}{|c|c|c|c|c|c|c|c|}
\hline \multirow[b]{2}{*}{ Handedness } & \multicolumn{2}{|c|}{ Symptoms worse in } & \multicolumn{3}{|c|}{ Bilateral } & \multirow[b]{2}{*}{ Total } & \multirow{2}{*}{$\begin{array}{l}\text { Worse in non- } \\
\text { dominant hand }\end{array}$} \\
\hline & $\mathrm{R}$ only & L only & Equal & $\mathbf{R}>\mathbf{L}$ & $\mathbf{L}>\mathbf{R}$ & & \\
\hline \multirow[t]{2}{*}{ Right } & 411 & 168 & 449 & 962 & 423 & 2413 & $24 \%$ \\
\hline & $17 \%$ & $7 \%$ & $19 \%$ & $40 \%$ & $18 \%$ & & \\
\hline \multirow[t]{2}{*}{ Left } & 15 & 29 & 19 & 41 & 88 & 192 & $29 \%$ \\
\hline & $8 \%$ & $15 \%$ & $10 \%$ & $21 \%$ & $46 \%$ & & \\
\hline \multirow[t]{2}{*}{ Ambidextrous } & 5 & 6 & 17 & 14 & 16 & 58 & \\
\hline & $9 \%$ & $10 \%$ & $29 \%$ & $24 \%$ & $28 \%$ & & \\
\hline Total & 426 & 197 & 468 & 1003 & 511 & 2605 & $25 \%$ \\
\hline
\end{tabular}

Pearson $\chi^{2}$ statistic for independence: 120.8 on four degrees of freedom, $\mathrm{p}<0.001$.

$L$, left; $R$, right.

differences in incidence between countries deserves further study.

Both the Canterbury and the Huddersfield data clearly show a bimodal age distribution for carpal tunnel syndrome. This is most pronounced for women but is also seen in men, particularly in the Huddersfield data. In East Kent the early peak in men is clear in the raw patient numbers at 51 years, but the smoothing effect of converting this population to 10 year age bands for age adjustment renders the peak only a modest hump in the age adjusted incidence data. This pattern is essentially similar to that reported for carpal tunnel decompressions in Canada, ${ }^{16}$ though with a more pronounced peak in the elderly, but is clearly different from the general portrayal of the age incidence in the wider literature.

Carpal tunnel syndrome in the elderly appears relatively neglected in most published series, perhaps because it is now widely believed to be a disorder of middle aged women and the diagnosis is therefore considered less readily in the elderly. The disorder tends to be more severe, and may even progress more rapidly, in the elderly. Figure 4 shows the mean neurophysiological severity in relation to age and reveals the advanced nature of the disease in the retired population. Advanced age is a poor prognostic factor for surgical treatment of carpal tunnel syndrome, but only weakly so. Of 565 patients over the age of 65 who were asked about the outcome of their carpal tunnel decompression, $69 \%$ of those operated on at or before grade 4 reported a satisfactory outcome, compared with only $52 \%$ of those who had reached grade 5 or $6 .{ }^{22}$ Patients should not be denied treatment purely because of age.

Three quarters of all patients with carpal tunnel syndrome have more severe symptoms in their dominant hand at first presentation. First presentation with symptoms in the nondominant hand should prompt a review of the diagnosis

Table 5 Relation between side of worst subjective symptoms and side of worst neurophysiological abnormality in carpal tunnel syndrome

\begin{tabular}{llll}
\hline & \multicolumn{3}{l}{ Side subjective symptoms worse } \\
\cline { 2 - 4 } $\begin{array}{l}\text { Side nerve conduction } \\
\text { studies result worse }\end{array}$ & Right & Equal & Left \\
\hline Right & 2885 & 455 & 215 \\
Column percentage & $78 \%$ & $37 \%$ & $11 \%$ \\
Equal & 584 & 504 & 397 \\
Column percentage & $16 \%$ & $41 \%$ & $19 \%$ \\
Left & 215 & 274 & 1434 \\
Column percentage & $6 \%$ & $22 \%$ & $70 \%$ \\
Total & 3684 & 1233 & 2046 \\
\hline Simple $\kappa=0.497$, ASE $0.0085, \mathrm{p}<0.0001$. &
\end{tabular}

unless there is an obvious cause for median nerve entrapment on that side, such as a wrist fracture. There is good agreement between the subjective assessment of which is the worst side and neurophysiological assessment of median nerve impairment, and thus neurophysiological abnormalities also tend to lateralise to the dominant hand.

Figure 1 shows a definite increase in the diagnosis of carpal tunnel syndrome during the 1990s. It is impossible to be certain whether the increasing overall incidence is genuine or simply an effect of greater case ascertainment. However, the mean severity of these cases has been declining, suggesting that we are perhaps making the diagnosis earlier, possibly because of increasing awareness by general practitioners. The provision of direct access to the neurophysiology service from primary care has proved very popular and may well have drawn attention to more cases at an earlier stage.

Figure 1 also shows an apparently high and increasing rate of surgical treatment for carpal tunnel syndrome in East Kent. The total figures of 6246 neurophysiologically confirmed cases and 4646 operations would appear at first to suggest that $74 \%$ of cases are being treated surgically. However, several factors make this assumption invalid. First, some neurophysiologically negative cases are treated surgically. Second, the surgery data do not distinguish between unilateral and bilateral procedures, and a patient who has the left and right sides decompressed on separate visits will appear as two operations. Third, some patients return for second operations on the same hand after initial failure and are also thus counted twice. It is likely that the true rate of conservative treatment is much higher than $26 \%$.

The success rate of surgical treatment falls once the syndrome advances beyond Canterbury grade $4 .{ }^{22}$ The distribution of severity (fig 5) shows that we are detecting $75 \%$ of cases at or before grade 4 , but a quarter of all patients are still presenting at a sufficiently late stage that their chances of successful treatment have been prejudiced, with approximately $7 \%$ having reached the end stage of grade 6 .

\section{Authors' affiliations}

J D P Bland, Regional Department of Clinical Neurophysiology, Kent and Canterbury Hospital, Canterbury, UK

S M Rudolfer, Department of Mathematics, University of Manchester, UK

Competing interests: none declared

\section{REFERENCES}

1 Phalen GS. The carpal-tunnel syndrome: seventeen years' experience in diagnosis and treatment of six hundred and fifty-four hands. 1966:48A:211-28

2 Phalen GS. Reflections on 21 years' experience with the carpal-tunnel syndrome. JAMA 1970;212:1365-7.

3 Ferry S, Pritchard T, Keenan J, et al. Estimating the prevalence of delayed median nerve conduction in the general population. Br J Rheumatol $1998 \cdot 37 \cdot 630-5$ 
4 de Krom MC, Knipschild PG, Kester AD, et al. Carpal tunnel syndrome, prevalence in the general population. J Clin Epidemiol 1992;45:373-6. 5 Atroshi I, Gummesson C, Johnsson R, et al. Prevalence of carpal tunnel syndrome in a general population. JAMA 1999;282:153-8.

6 Nordstrom DL, DeStefano F, Vierkant RA, et al. Incidence of diagnosed carpal tunnel syndrome in a general population. Epidemiology 1998;9:342-5.

7 Stevens JC, Sun S, Beard CM, et al. Carpal tunnel syndrome in Rochester Minnesota, 1961-1980. Neurology 1988;38:134-8.

8 Katz JN, Larson MG, Fossel $\mathrm{AH}$, et al. Validation of a surveillance case definition of carpal tunnel syndrome. Am J Public Health 1991:81:189-93.

9 Rempel D, Evanoff B, Amadio PC, et al. Consensus criteria for the classification of carpal tunnel syndrome in epidemiologic studies. Am J Public Health 1998;88:1447-51

10 Loscher WN, Auer-Grumbach M, Trinka E, et al Comparison of second lumbrical and interosseus latencies with standard measures of median nerve function across the carpal tunnel: a prospective study of 450 hands. I Neurol 2000;247:530-4.

11 Uncini A, Di Muzio A, Awad J, et al. Sensitivity of three median to ulnar comparative tests in diagnosis of mild carpal tunnel syndrome. Muscle Nerve 1993; 16:1366-73.

12 Redmond M, Rivner H. False positive electrodiagnostic tests in carpal tunnel syndrome. Muscle Nerve 1988;11:511-17

13 Anonymous. Practice parameter for carpal tunnel syndrome. Neurology 1993:43:2406-9.
14 Silverstein B, Welp E, Nelson N, et al. Claims incidence of work related disorders of the upper extremities: Washington State 1987-1995. Am J Public Health 1998;88:1827-33.

15 Mondelli M, Giannini F, Giacchi M. Carpal tunnel syndrome incidence in a general population. Neurology 2002;58:289-94.

16 Liss GM, Armstrong C, Kusiak RA, et al. Use of provincial health insurance plan billing data to estimate carpal tunnel syndrome morbidity and surgery rates. Am J Ind Med 1992;22:395-409.

17 Bland JDP. The value of the history in the diagnosis of carpal tunnel syndrome. $J$ Hand Surg Br 2000;25B:445-50.

18 Bland JDP. A neurophysiological grading scale for carpal tunnel syndrome. Muscle Nerve 2000;23:1280-3.

19 Rudolfer SM. PATIENTS.DAT, a dataset involving the diagnosis of carpal tunnel syndrome. Technical report 2001/07: Manchester Centre for Statistical Science, 2001.

20 Kouyoumdjian JA. [Carpal tunnel syndrome: sensory median-radial difference versus conduction studies in 1059 hands (668 cases)]. Arq Neuropsiquiatr 1998;57:208-15, [In Portuguese].

21 Ahn DS, Yoon ES, Koo SH, et al. A prospective study of the anatomic variations of the median nerve in the carpal tunnel in Asians. Ann Plast Surg 2000;44:282-7

22 Bland JDP. Do nerve conduction studies predict the outcome of carpal tunnel decompression? Muscle Nerve 2001 ;24:935-40.

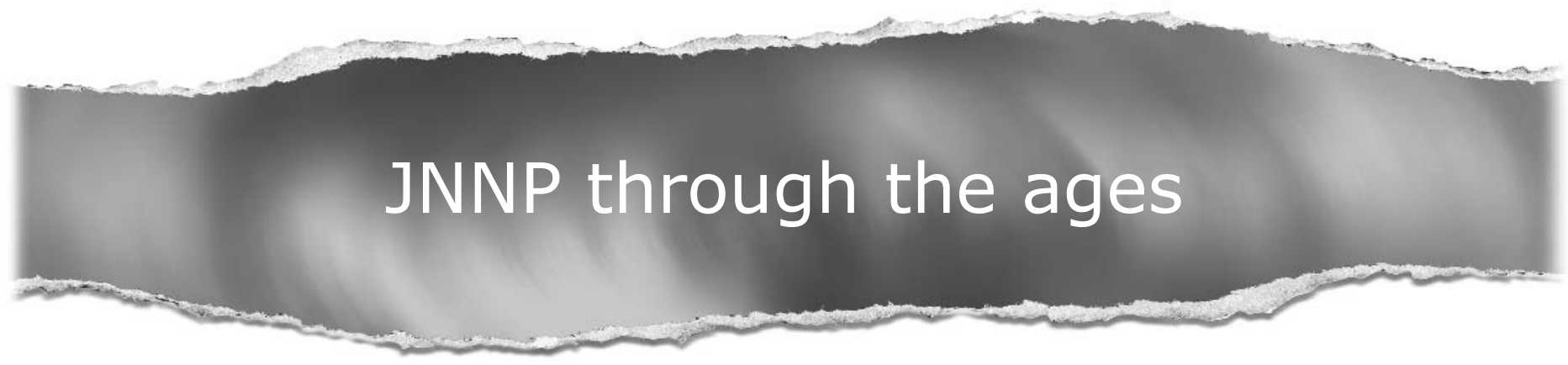

Browse the Archive

Journal of Neurology, Neurosurgery, and Psychiatry online has an archive of content dating back to 1966.

Full text from 1997; abstracts from 1975; table of contents from 1966

www.jnnp.com 